\title{
Area-Level Variation in Children's Unmet Need for Community-Based Mental Health Services: Findings from the 2014 Ontario Child Health Study
}

DOI:

10.1007/s10488-020-01016-3

\section{Document Version}

Accepted author manuscript

Link to publication record in Manchester Research Explorer

\section{Citation for published version (APA):}

Duncan, L., Georgiades, K., Reid, G. J., Comeau, J., Birch, S., Wang, L., \& Boyle, M. H. (2020). Area-Level Variation in Children's Unmet Need for Community-Based Mental Health Services: Findings from the 2014 Ontario Child Health Study: Findings from the 2014 Ontario Child Health Study. Administration and Policy in Mental Health and Mental Health Services Research. https://doi.org/10.1007/s10488-020-01016-3

\section{Published in:}

Administration and Policy in Mental Health and Mental Health Services Research

\section{Citing this paper}

Please note that where the full-text provided on Manchester Research Explorer is the Author Accepted Manuscript or Proof version this may differ from the final Published version. If citing, it is advised that you check and use the publisher's definitive version.

\section{General rights}

Copyright and moral rights for the publications made accessible in the Research Explorer are retained by the authors and/or other copyright owners and it is a condition of accessing publications that users recognise and abide by the legal requirements associated with these rights.

\section{Takedown policy}

If you believe that this document breaches copyright please refer to the University of Manchester's Takedown Procedures [http://man.ac.uk/04Y6Bo] or contact uml.scholarlycommunications@manchester.ac.uk providing relevant details, so we can investigate your claim.

\section{OPEN ACCESS}




\section{Administration and Policy in Mental Health and Mental Health Services Research \\ Geographic variation in children's mental health service targeting: Findings from the 2014 Ontario Child Health Study \\ --Manuscript Draft--}

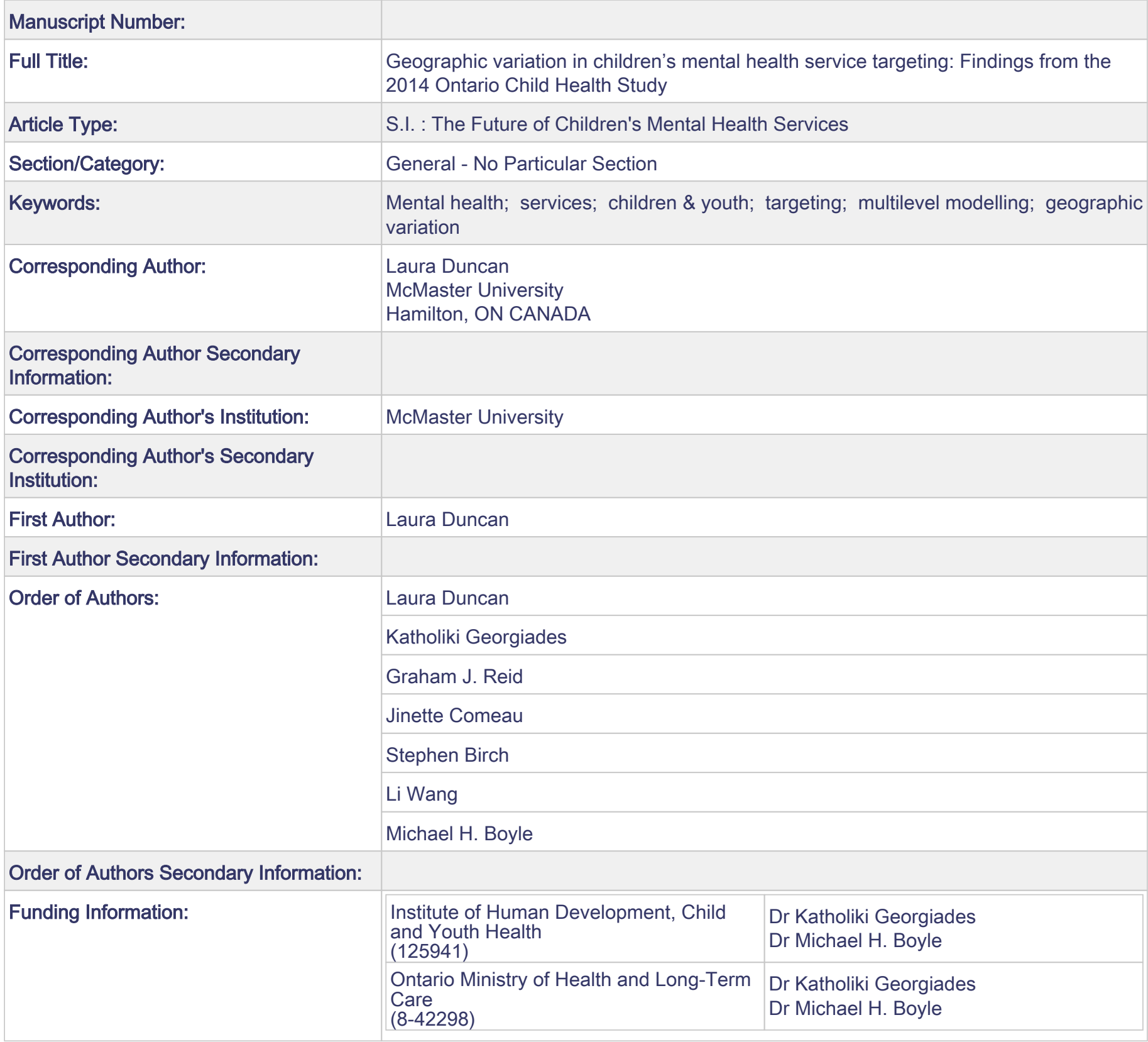


Running head: GEOGRAPHIC VARIATION IN SERVICE TARGETING

Geographic variation in children's mental health service targeting:

Findings from the 2014 Ontario Child Health Study

Laura Duncan, Katholiki Georgiades, Graham J. Reid, Jinette Comeau, Stephen Birch, Li Wang, Michael H. Boyle

Author note

Stephen Birch, PhD

Professor, Centre for the Business and Economics of Health, University of Queensland, Brisbane, Australia

Centre for Health Economics, University of Manchester, Manchester, UK

Professor Emeritus, Centre for Health Economics and Policy Analysis, McMaster University, Hamilton, ON, Canada

Michael H. Boyle, PhD

Professor Emeritus, Offord Centre for Child Studies, Department of Psychiatry and Behavioural Neurosciences, McMaster University, Hamilton, ON, Canada

Jinette Comeau, $\mathrm{PhD}$

Assistant Professor, Children's Health Research Institute, Department of Sociology, King's University College at Western University, London, ON, Canada

Laura Duncan, MA, (contact author)

PhD student. Offord Centre for Child Studies, Department of Psychiatry and Behavioural Neurosciences, McMaster University, Hamilton, ON, Canada Department of Health Research Methods, Evidence \& Impact (formerly Clinical Epidemiology \& Biostatistics), McMaster University, Hamilton, ON, Canada 1280 Main St W, MIP 201A, Hamilton, ON, L9S 4K1; 9055259140 x21500;

duncanlj@mcmaster.ca

Katholiki Georgiades, $\mathrm{PhD}$

Associate Professor, Offord Centre for Child Studies, Department of Psychiatry and Behavioural Neurosciences, McMaster University, Hamilton, ON, Canada 
Graham J. Reid, PhD

Departments of Psychology, Family Medicine and Paediatrics, Schulich School of Medicine and Dentistry, The University of Western Ontario; Scientist, Children's Health Research Institute.

Li Wang, PhD

Analyst, Offord Centre for Child Studies Department of Psychiatry and Behavioural Neurosciences McMaster University, Hamilton, ON, Canada

This paper has not been presented at a meeting.

Submission date: June $6^{\text {th }}, 2019$

Funding: The 2014 Ontario Child Health Study was funded by research operating grant 125941 from the Canadian Institutes of Health Research (CIHR), Health Services Research Grant 842298 from the Ontario Ministry of Health and Long-Term Care (MOHLTC) and from funding from MOHLTC, the Ontario Ministry of Children and Youth Services and the Ontario Ministry of Education. Dr. Boyle was supported by CIHR Canada Research Chair in the Social Determinants of Child Health, Dr. Georgiades by the David R. (Dan) Offord Chair in Child Studies and Dr. Reid by the Children's Health Foundation.

Conflict of Interest: The authors declare that they have no conflict of interest.

Acknowledgements: The authors would like to thank the Ontario Ministry of Children, Community and Social Services (formerly the Ministry of Children and Youth Services) for providing administrative data used in the analysis. 


\title{
GEOGRAPHIC VARIATION IN SERVICE TARGETING
}

\begin{abstract}
Using individual-level general population data, area-level government administrative data and Census data from Ontario, Canada, we: 1) examine geographic variation in children's mental health service targeting, and 2) identify area-level system and environmental predictors of targeting amenable to policy intervention. Geographic inequity was uncovered comparing Toronto to the rest of Ontario and based on rurality. Of the area-level system predictors, higher proportions of service-users in an area receiving intensive services and higher area levels of satisfaction with services and resources were associated with increased odds of targeting. Higher area levels of antisocial behaviour were associated with a reduced odds of targeting.
\end{abstract}

Key words: Mental health, services, children \& youth, targeting, multilevel modelling, geographic variation 
Geographic variation in children's mental health service targeting:

Findings from the 2014 Ontario Child Health Study

The ability of children's mental health services to address the needs of children and youth (herein child/ren) depends on services being used by those with a mental health need. In a service system designed to address mental health need, all children with a mental health need would have access and would use appropriate mental health services. However, evidence shows that $13 \%$ of Canadian children aged 4 to 17 years have mental disorders but only $31 \%$ of these children are receiving specialized mental health services (Waddell, Shepherd, Schwartz, \& Barican, 2014; Georgiades et al., 2019). The extent to which services for mental health are used by those with a mental health need can be labelled service targeting. Appropriate targeting occurs when children with a mental health need use services and conversely, when children without a mental health need are not using services. Mistargeting occurs when children with need are not accessing and using services and also when children without need are using services. There are studies focusing on children with a mental health need who are not using services (Flisher et al., 1997; Kataoka, Zhang, \& Wells, 2002; Newacheck, Hughes, Hung, Wong, \& Stoddard, 2000), but the converse, (children without need who are using services) is understudied and must be included in order to understand the full spectrum of service targeting and mistargeting.

How mental health need is conceptualized and defined impacts how service targeting is understood. Bradshaw's (1972; 2005) typology of need proposes six need types: normative (presence of mental disorder); felt (subjective perception of a mental health problem); expressed (demand for mental health service); comparative (population inequities in mental health); medical (treatable disease) and social (restoring quality of life). However, a consensus on the 
appropriate definition of need in children's mental health does not exist. Further, there is evidence to suggest that perceptions of a mental health need (felt need) are more closely associated with service demand than the presence of diagnosed mental health disorder (normative need; Wichstrøm, Belsky, \& Jozefiak, 2014).

When considering geographic variation in targeting, comparing units of geography that align with government administrative jurisdictions responsible for the overall provision of services will make it possible for decision-makers to address mistargeting by making or changing policies around service provision or resource allocation. The existing evidence on geographic disparities in service targeting is limited. There are two studies: an ecological study from the United States (US) and an analysis of health administrative data from Canada. The US study defined a mental health need as 'assessed need' based on elevated scores on six items from the Child Behaviour Checklist (Achenbach, 1991) and found large variability in children's mental health service targeting between 13 states. There was no observable relationship between levels of need and the use of services across states (Sturm, Ringel, \& Adreyeva, 2003). The 2018 Canadian study examined geographic variation in mental health risk (defined as the occurrence of a doctor's visit for a symptom related to mental health rather than assessed need) and medical service use (physician visits and hospitalization) in 140 neighbourhoods in Toronto using administrative health data. They documented neighbourhood variation in both physician visits and hospitalizations (Law \& Perlman, 2018). Policy decisions about mental health services could be made very generally at the state/province level (e.g. overall allocations, state policy on service eligibility, pathways etc.) but are unlikely to be made at the neighbourhood level within a large city like Toronto. As such, these studies are of limited use from a policy perspective as the units of geography do not align with administrative boundaries commonly used for service governance 
and provision. In this study, we use government-defined service areas as our geographic boundaries, namely Ministry of Children, Community and Social Services (MCCSS) service areas. These geo-political areas are larger than neighbourhoods, smaller than states/provinces and the level at which: (a) children's mental health services are administratively organized, (b) policy is made, (c) resources are allocated, and (d) administrative data is collected.

Geographic variation in service targeting may reflect between-area variation in mental health need and services that is indicative of underlying service system inequities. The behavioural model of health service use put forward by Andersen $(1995 ; 2008$; Andersen \& Newman, 1973) conceptualizes use of health services as being determined by predisposing, enabling and need factors at the individual and area level. In the identification of area-level factors associated with service use, Andersen argues that for a variable to be useful in promoting access, it must be 'mutable' or tied to the creation of policy that could produce individual behavioural change. The factors with the highest level of mutability, according to Andersen, are 'enabling' factors, which, at the area level include policy, financing and organisation characteristics such as health service cost and location. Systematic reviews of the use of Anderson's behavioural model provide direction in the identification of candidate area-level variables (Phillips, Morrison, Andersen, \& Aday, 1998: Babitsch, Gohl, \& von Lengerke, 2012). Policy factors have centred on health insurance policies, particular in the US literature (Kataoka, Zhang, \& Wells, 2002; Newacheck, Hughes, Hung, Wong, \& Stoddard, 2000). Financing includes health services resources, expenditures and methods of compensating providers. Organisation includes the amount, varieties, locations, structures and distribution of health services facilities and personnel (Babitch, Gohl, \& von Lengerke, 2012). Phillips and colleagues (1998) also add environmental variables that include characteristics of the external environment 
such as economic climate, wealth, politics, stress and violence exposure, and societal norms. Area-level socio-demographic characteristics are useful from a descriptive perspective as important considerations in policy development aimed at improving targeting.

Studying geographic variation in service targeting adequately requires individual-level data on: (a) large numbers of respondents in numerous geographic areas, and (b) both service users and non-users. The lack of individual-level studies with sufficient coverage of areas of analysis and clustering of individuals within areas means that geographic analyses of mental health need and service use largely rely on ecological study designs. In ecological studies the unit of analysis is the geographic area and variables of interest are aggregate summary statistics at the area level. These designs are subject to criticism mainly due to challenges in statistical inference and interpretation due to the ecological fallacy (when area-level associations are mistakenly interpreted as representing individual-level associations), but also due to a lack of choice of accurate and appropriate area-level variables (Holley, 1998). Despite providing broad geographic coverage, administrative health databases such as those used in the Toronto study (Law \& Perlman, 2018) exclude children with a mental health need who are not accessing services, leading to an incomplete picture. The data provided by the 2014 Ontario Child Health Study (Boyle et al., 2019a), a large scale general population study, provide a unique opportunity to overcome the limitations of previous studies.

The objectives of this study are to describe the extent to which service targeting varies by geographic area, and to identify area-level predictors of targeting using government service areas as a level of geography that maximizes the potential for mutability. To do this we addressed two research questions: (1) Does service targeting vary by service area? (2) What system, environmental and socio-demographic service area-level characteristics are associated with 
GEOGRAPHIC VARIATION IN SERVICE TARGETING

service targeting? Findings from this study will provide much needed information to decisionmakers around the targeting of children's mental health services and could help frame service delivery policy development.

\section{Method}

\section{Data}

This study combines individual-level data from the 2014 Ontario Child Health Study (OCHS; Boyle et al., 2019a; Statistics Canada, 2017a) with aggregate service area-level data from: a) administrative records from the Ontario Ministry of Children \& Community and Social Services (MCCSS), b) household survey responses from the 2014 OCHS, c) the 2016 Canadian Census Profile (Statistics Canada, 2018). The 2014 OCHS is a province-wide, cross-sectional, epidemiological study of children's mental health. A probability sample of 6,537 households (50.8\% response) participated, with 10,802 children aged 4 to 17 . Using the 2014 Canadian Child Tax Benefit file as the sampling frame, households were selected based on a complex three-stage survey design that involved cluster sampling of residential areas and stratification by residency (urban, rural) and income (areas and households cross-classified by three levels of income). Data were collected during home visits by trained Statistics Canada interviewers from the person most knowledgeable (PMK) about the child and by computer-assisted interviews from children aged 12 to 17. Data collection occurred from October 2014 to October 2015. Detailed accounts of the survey design, content, training, and data collection are available elsewhere (Boyle et al., 2019a; Statistics Canada. 2017b).

\section{Concepts \& Measures}


Service targeting. Combining individual classifications of need with the

presence/absence of mental health agency service contact provided the basis for operationalizing the definition of targeting.

Mental health need. Children's mental health need was defined based on the presence of either normative (the presence of mental disorder) or felt need (subjective perceptions of a mental health need) as conceptualized by Bradshaw $(1972 ; 2005)$ in the previous six months, according to the PMK about the child. The PMK of one randomly selected child from each family $(n=6,537)$ was interviewed using the Mini International Neuropsychiatric Interview for Children and Youth (MINI-KID; Sheehan et al., 2010; Duncan et al; 2018). PMKs of all children $(n=10,802)$ were administered the OCHS Emotional Behavioural Scales (OCHS-EBS), a 52-item checklist that is self-reported by PMKs about children to assess mental health disorder symptoms over the past six months. The OCHS-EBS demonstrates satisfactory reliability and validity when used as either a dimensional (Duncan et al., 2018) or categorical (Boyle et al., 2018) measure. To convert OCHS-EBS scale scores to binary classifications of disorder, first, the MINI-KID was used to estimate disorder prevalence. Second, scale score cut-offs that produced a prevalence matching the same disorder prevalence assessed by the MINI-KID interview were selected. These cut-offs were then applied to the OCHS-EBS scale scores. Children meeting criteria for one or more disorders in the past six months according to the PMK report binary classifications of the OCHS-EBS were classified with normative need ( $1=$ present, $0=a b s e n t)$.

Felt need was defined as positive responses to two sequenced questions that asked whether the PMK thought that, in the past six months, (a) the child had any emotional or behavioural problems, and (b) if yes, needed any professional help with these problems. Felt need was coded as $1=$ present if the parent answered yes to both questions. Children with 
normative and/or felt need were coded as 1=having a mental health need; while those with neither were coded as $0=$ no mental health need.

Contact with mental health services. This was based on PMK responses to the question 'In the past six months, did you, another family member or $<$ child's name $>$ see or talk to anyone from any mental health or addictions agency because of concerns about his/her mental health?'. In responding to this question, PMKs were asked if they had contact with specific, named MCCSS-funded mental health or addictions agencies in their service area (Reid et al., 2008). This was coded 1 if the PMK answered yes, and 0 if they answered no. Given our focus on MCCSS service areas, we isolated MCCSS-based service contact from other types of mental health service contact. Hospital, physician and school-based services were excluded in our definition of contact with mental health services.

Service targeting. This was coded $1=$ child had (a) no mental health need and no service contact, or (b) a mental health need and service contact; and $0=$ child had (a) a mental health need but no contact with services, or (b) no mental health need and contact with services. This variable serves as the dependent variable in all models.

Service area-level variables. Our analysis focuses on the 33 Ontario Ministry of Children, Community and Social Services (MCCSS) 'service areas' that are geographically bounded in one or more Statistics Canada Census Divisions. Within service areas, the government contracts with individual service agencies to provide programs targeting the identification of mental health problems, as well as individual-, family-, and group-based interventions for these problems (Government of Ontario, 2015).

System characteristics. Government administrative data provided from the Client Services Branch of MCCSS for the 2015-16 fiscal year was used to assess: a) the number of 
MCCSS-funded children's mental health agencies providing services within each service area, b) total service area expenditures (in CAD\$s), and c) the types of services received according to the Ontario government core service definition (Government of Ontario, 2015). This variable was constructed using the total number of children using a mental health agency within a service area as the denominator to calculate the percentage of clients across agencies in the service area who received brief, counselling/therapy, crisis or intensive treatment services, measured in $10 \%$ increments. It should be noted that these groups are not mutually exclusive; children could receive any one of these four types of services.

Of the 33 service areas, Toronto was determined to be an extreme outlier with a much larger number of children, number of children's mental health agencies, and service expenditures. Because of this, a binary variable $(1=$ Toronto, $0=$ all other area $)$ was included as an important system variable.

Environmental characteristics. Questions from the 2014 OCHS asking PMKs to rate aspects of their neighborhood were aggregated to the service area level to characterize service areas. Variables were generated by computing aggregated weighted means at the service area level—weighted using dwelling sampling probability weights provided by Statistics Canada. For the questions contributing to both antisocial behaviour and satisfaction with services and resources, PMKs were able to select "Not Applicable" which resulted in missing data (approximately $7 \%$ missing data on all items). All available data was used to generate aggregate variables.

Antisocial behaviour. This is a cumulative risk variable comprised of a count of positive responses to four questions. Each question begins, 'While you have lived in this neighbourhood...' and the PMK is asked about household members experiences of assault, 
repeated verbal insult or disrespect, theft from household property, or household break-in. Positive responses were summed to form a count from 0 to 4 .

Satisfaction with services and resources. This is based on responses to five questions that were part of a group of questions asking about how satisfied the respondent was with different aspects of their neighbourhood. The five items selected asked about quality of schools, child care services, health care services, recreation facilities and public transport. Response options went from ' $0=$ very dissatisfied' to ' $3=$ very satisfied' and were summed to create a score from 0 to 15 .

Socio-demographic characteristics. Area-level socio-demographic characteristics were derived from the 2016 Census Profile at the Census Division level (Statistics Canada, 2018). Census variables included the number of children in the service area aged 0 to 18 (in 10,000s), percentage of immigrants (individuals born outside Canada), the percentage of single parent families, the percentage of dwellings that were rented (vs. owned), the percentage of rural population (vs. small, medium and large urban) and mean household income. Percentages are measured in $10 \%$ increments.

\author{
Analysis \\ Multilevel, random intercept binary logistic regression models were used to analyze \\ children's mental health service targeting among children (level 1) nested with service areas \\ (level 2). To address the first research question about whether service targeting varies by service \\ area, a null random intercept model was estimated. By specifying a random intercept in the \\ model, it is possible to estimate the amount of between-area variation in service targeting. To \\ visualize differences between areas in targeting, we plotted the area level residuals (random \\ effects) from this null model to observe the extent to which specific service areas deviate from
}


overall mean levels of targeting. To answer the second research question, we added potential predictor variables to the model.

Twenty-eight of the 33 Ontario Service Areas were represented in the 2014 OCHS data. The stratified, cluster sampling design of the OCHS meant there was a trade-off between: (a) sufficient clustering of families within areas to examine contextual effects, and (b) coverage of families within all areas. Due to the clustering, there were five service areas that contained no survey respondents. There is no consensus on the minimum number of level 2 units needed in multilevel models. Recommendations range from 10 (McNeish \& Stapleton, 2016) to 30 (Kreft, 1996) and depend on the overall available sample, the within-area sample size, and the research question. Twenty-eight service areas are sufficient for estimating random effects, but this number limits the ability to look at more than one or two area-level predictors in a model at a time. Therefore we were only interested in unadjusted associations so service area-level predictors were added and assessed one at a time. The number of children per area ranged from approximately 50 to 2,500 which meets the minimum sample size requirement of 50 required to estimate unbiased level 2 standard errors (Maas \& Hox, 2005).

Sampling weights based on the probability of being selected and participating in the study were applied at the child level. To account for the complex survey design, mean bootstrap weights were applied with an adjustment factor to produce accurate standard errors for childlevel variable descriptives. Area-level weights were not needed as all area-level variables were either population estimates or weighted aggregates representing population-level estimates. The analysis was conducted in MLwiN version 2.35 (Rasbash, Steele, Browne, \& Prosser, 2004). The null model was fitted using 1st order marginal quasi-likelihood procedures and iterative generalized least squares estimation. Subsequent models were fitted using 2nd order predictive 
quasi-likelihood as recommended by Rasbash and colleagues (2004) to deal with issues of downward biased estimates. Significance in all models was assessed using a Wald test. Ideally a likelihood ratio test would be conducted but discrete response models in MLwiN are estimated using quasi-likelihood methods making the likelihood value unreliable (Rasbash, Steele, Browne, \& Prosser, 2004). Significance is assessed against three levels: $p<0.05(*), 0.01(* *)$ and $0.001(* * *) . P$ values were adjusted using the Benjamini and Hochberg (1995) method to account for multiple testing.

Sample for analysis. All 2014 OCHS respondents were eligible for inclusion in the analysis. There were 37 respondents $(0.3 \%)$ missing data on the variables needed to derive targeting who were omitted from the analysis.

\section{Results}

Table 1 shows the weighted sample characteristics for children and service areas and the range of observed values for service area characteristics. Almost $20 \%$ of the sample were classified as having a mental health need and 3.5\% had contact with a children's mental health agency. Eighty-three percent of the sample had appropriate service targeting and the majority of this group are those children without need and service contact. Seventeen percent of children experienced service mistargeting; $16.5 \%$ had a mental health need and no service contact and $0.8 \%$ had no mental health need but were in contact with mental health services. A supplementary table in the Appendix shows the service area characteristics by service area.

\section{Does service targeting vary by service area?}

To answer this question we fitted a null random intercept model to the data. The coefficient and standard error (SE) for the random effect is $0.094(\mathrm{SE}=0.032)$ and significant at the $p<0.01$ level (results not shown in table). Following the procedures for calculating the 
variance partition coefficient outlined by Rasbash et al. (2004), this means $2.78 \%$ of the overall variance in mistargeting was attributable to between-service area differences. Thus, service targeting varies a small amount by service area.

To visualize the random effects, we estimated and plotted the area level standardized residuals from the null model. Figure 1 shows the plot of residuals in ascending order, from the lowest levels of targeting to the highest, along with their $95 \%$ confidence limits. These residuals represent how far service area levels of targeting depart from the overall mean (the dotted line in the middle of the graph reflects mean service targeting in Ontario). The confidence intervals around the residuals for Toronto, Essex, York, Halton, Peel, Durham (higher targeting), and Haliburton/Kawartha Lakes/Peterborough (lower targeting) service areas do not overlap zero, which means that these service areas differ significantly from the provincial mean at the $p<0.05$ level.

\section{What system, environmental and socio-demographic service area-level characteristics are associated with service targeting?}

Table 2 presents the unadjusted odds ratios and their $95 \%$ confidence intervals for the fixed effects in binary logistic multilevel regression models. All system characteristics were associated with service targeting. The odds of targeting were increased in areas with greater mental health service expenditures and more mental health agencies. The odds of targeting increased by $1 \%$ as: (a) expenditures increase by $\$ 1 \mathrm{M}$, and (b) the number of agencies increases by one. Looking at service types, higher proportions of clients receiving intensive services are associated with increased odds of targeting; as the percentage of clients receiving intensive services increases by $10 \%$, the odds of targeting increases by $7 \%$. Finally, being in the Toronto service area compared to all other areas increased the odds of targeting by $75 \%$. 
Looking at environmental characteristics, increased levels of antisocial behaviour more than halved the odds of targeting; however the large size of the effect is due partially to small range of observed values (0.13-1.12 for the antisocial behaviour variable). Higher levels of satisfaction with area resources were associated with a $28 \%$ increased odds of service targeting.

Among the socio-demographic characteristics examined, the odds of targeting increased by $1 \%$ as the number of children in the service area increased by 10,000 . A $10 \%$ increase in the immigrant population was associated with a $1 \%$ increase in the odds of targeting. A $10 \%$ increase in the percentage of rural population (vs. urban) was associated with a 10\% decrease in the odds of targeting. Higher mean income was associated with increased odds of targeting; as mean income increases by $\$ 10,000$, targeting increased by $14 \%$.

Sensitivity Analysis. Toronto is an outlier in population size, expenditures and number of agencies and had a large unadjusted association with targeting. Thus, we re-examined our models adjusting for the Toronto service area to see if it had an effect on the results. Once Toronto was included the model, the effects associated with mental health services expenditures, number of mental health agencies and number of children do not reach statistical significance at the $p<0.05$ level. All other effects remain in the same direction and of a similar magnitude and level of significance (results not shown).

\section{Discussion}

This study is the first that we are aware of to use individual-level data in a multilevel analysis of area-level mental health service targeting. Adequate service targeting can provide an indication of responsiveness of the mental health system to population need. Responsiveness has been identified as an intrinsic goal of health care systems, together with health outcomes and financial fairness (World Health Organization, 2000). A health system that is able to respond to 
the needs of its users serves a number of overarching population health policy principles including health equity, accountability and efficiency (Bhattacharya \& Bhatt, 2017). On the other hand, poor targeting could indicate inequity in how services are organized, funded or accessed or problems with the mechanisms through which individuals use services. Appropriate service targeting requires addressing and reducing these system issues In identifying the extent to which there is geographic variation in targeting and which service area-level characteristics are associated with targeting, this study can help governments and policy makers support equitable access to mental health services for children and in need.

\section{Geographic variation in service targeting}

Service targeting can be understood as the extent to which there is a match between individual mental health need and service use. A mismatch could be a function of: (a) a lack of service availability, access or use, or (b) the use of services by those that do not exhibit a need. A unique aspect of this study is the inclusion of children who did not have a mental health need according to our definition, but who were in contact with our services. This group may be worthy of independent examination but unfortunately, this group only constituted $0.8 \%$ of our sample.

This study found small between-area differences in service targeting; approximately $3 \%$ of the variation in targeting was explained by between service area differences, which suggests that factors influencing targeting exert the same influence across service areas. However, the low levels of variability are likely due to the relatively small number and large size of service areas in the analysis. We examined differences between areas in levels of service targeting and found some areas did differ significantly from the provincial mean. It's important to note that while this helps us to understand how areas compare to each other, it does not help us understand how areas compare to the ideal scenario of perfect service targeting where $100 \%$ of children with 
a mental health need are accessing services and $100 \%$ of children without a need are not in contact with services. From a policy perspective, the overall ranking of areas is useful when considering where efforts to improve targeting should be focused.

\section{System, environmental and socio-demographic service area-level characteristics associated with service targeting}

We used Andersen's behavioural model of service use (Andersen 1995; 2008; Andersen \& Newman, 1973) to identify potential 'enabling' system, environmental, and sociodemographic contextual characteristics. Service system expenditures, size, types of services received by service users (system characteristics), area antisocial behaviour, satisfaction with services (environmental characteristics), number of children, immigrant composition, rurality, and mean household income of the service area (area socio-demographic characteristics) have an effect on service targeting. The Toronto service area was highly associated with increased targeting.

Targeting was increased in service areas characterized by more children, higher service expenditures and more agencies. However, these results become non-significant after Toronto was included in the models, suggesting it is a 'Toronto effect' that is driving these results. Living in the provincial capital of Ontario - the largest urban centre in Canada — is associated with a significantly higher likelihood of targeted services. Toronto has many more mental health agencies and more service funding, but also more children to serve. Compared to other service areas in Ontario, Toronto appears to be better able to match contact with mental health services to children exhibiting a need according to our definition. This is not surprising, given that access and availability of children's mental health services is likely to be better in a city that is better resourced and has numerous agencies. Public transit options facilitate families getting to 
agencies, while staff at agencies also have options to refer families to a number of specialized mental health hospitals and university-based research centres for information, advice or treatment. It could be argued that the fact that Ontario's provincial government offices are located in Toronto could also be exerting a positive impact on service provision although there is no formal, additional oversight from MCCSS in Toronto.

Our findings also demonstrate a reduced odds of service targeting in rural versus urban areas. Service areas with a larger rural population were associated with reduced odds of targeting; this effect remained even when we controlled for Toronto $(\mathrm{OR}=0.92$ [95\%CI=0.870.98]). Five of the service areas with significantly increased levels of targeting compared to the provincial mean are all highly populated, mostly urban areas (Toronto, York, Halton, Peel and Durham). The only service area that had significantly decreased odds of targeting compared to the provincial mean was Haliburton/Kawartha Lakes/Peterborough whose population is 50\% rural. This is consistent with previous research documenting urban-rural health inequities in Canada (Pong, DesMeules, \& Lagacé, 2009; DesMeules et al., 2006; Mitura \& Bollman, 2004, Nagarajan, 2004). It is also consistent with increased challenges of providing children's mental health services in rural versus urban areas (Boydell et al., 2007; Howell \& McFeeters, 2008). This finding suggests that decision-makers need to do more to support mental health service provision in rural areas as agencies may have to do more work to ensure that services are appropriately targeted. This could mean service outreach, mental health promotion and literacy, clearer service pathways and referral processes. This finding appears discrepant with a recent 2014 OCHS-based analysis of mental health and service use (Georgiades et al., 2019) which found that children with a mental health disorder were more likely to have contact with services in small-medium urban compared to large urban centres. This discrepancy is likely attributable to 
different approaches to operationalizing mental health need (mental health disorder only versus mental health disorder and perceived need in this analysis) and service contact (MCCSS-funded, hospital and school-based services versus MCCSS-funded services only in this analysis). There is particular concern about health and health service inequities in Indigenous and Northern communities in Ontario and Canada that tend to be in remote or rural areas (Canadian Mental Health Association, 2009). There were three service areas in our analysis that could be considered Northern Ontario communities: Thunder Bay, Greater Sudbury/Manitoulin/Sudbury, and Kenora/Rainy River. We examined differences in service targeting in a post hoc analysis by comparing this group of northern services areas to all other non-northern service areas. We did not find any significant effect (at $p<0.05$ ) in the comparison.

The Ontario government collects information from agencies about the proportion of their clients that receive different types of services, based on their core service definitions (Government of Ontario, 2015). We found that, of children receiving services, when higher proportions of children were receiving intensive treatment services, there was an increased odds of service targeting. Intensive treatment services are focused on the reduction of psychological, emotional, social and behavioural problems and could include residential or hospital-based inpatient care. The increased likelihood of targeting associated with increased proportions of children receiving these types of services could be explained by the level of severity of the presenting concerns. Intensive services are likely to be a response to critical concerns that, being more serious, are easier to identify and address than less severe forms of psychopathology that might be better suited to brief services, counselling or therapy treatments. It could also be the case that these other types of services are more suited to early intervention efforts where children 
receiving services may not meet criteria for a mental health diagnosis or perceive a need for professional help.

In addition to mental health service system characteristics, external environmental characteristics have also been identified for their role in interfering with an individual's ability to access appropriate services (Phillips, Morrison, Andersen, \& Aday, 1998; Anderson \& Newman, 1973). Exposure to stress, instability or violence could impact service use (Fleury et al., 2012). We found that targeting was reduced in areas with higher levels of antisocial behaviour — an indicator of environmental stress or violence. Previous research showed more mental health problems (particularly externalizing problems) for children exposed to antisocial behaviour in their neighbourhood environments (Boyle et al., 2019b). It appears that the negative effects of area-level antisocial behaviour also extend to service targeting, where higher levels of area-level antisocial behaviour significantly reduced the odds of services being appropriately targeted. Therefore, reducing environmental instability and violence should be a focus of policy intervention by governments that want to improve children's mental health and service access. Future work in this area should also consider whether service targeting is concentrated among children with specific types of mental health problems (e.g. externalizing vs. internalizing).

We also found that higher levels of satisfaction with other neighbourhood services and resources such as schools, child care and health care services was associated with better service targeting. This suggests that in areas where targeting is worse, other service supports are likely to also be rated as unsatisfactory. This could be a result of unclear or even dysfunctional referral processes between schools or doctors offices and specialized mental health services. We only assessed satisfaction with, and not use of, these other services; nevertheless our findings indicate 
that there may be broader issues with these public resources in terms of quality or availability that should be closely examined for systemic organisation or funding issues.

Another objective of this study was to examine selected socio-demographic characteristics that might help describe areas that have better targeting. There was no effect found for the percentage of single parent families and rental dwellings; we did find rurality effects, as discussed above. There was a small increase in the odds of targeting in areas with more children and larger immigrant populations. There was also an income effect whereby each $\$ 10,000$ increase in mean household income was associated with a $14 \%$ increase in the odds of targeting. This aligns with existing evidence showing income gradients across health problems and health service use (Flisher et al., 1997). Of note, all MCCSS services in Ontario are free. Thus, the findings related to income do not reflect the ability to pay for services. Rather, individuals in regions with high incomes may have more positive attitudes about mental health services (less stigma) along with the knowledge and means (e.g., transportation, ability to take time off work) to access services.

\section{Limitations}

This is the first study to examine the impact of contextual, area-level characteristics on individual-level service targeting. Although this study addresses the limitations of ecological analysis and goes beyond the existing literature to cover new ground in the field of geography and mental health, it is not without limitations. First, the targeting variable used in the analysis does not measure the extent or depth of targeting or mistargeting. Children and families be under- or over-served based on their needs to differing extents and our definition does not capture this. 
Second, we did not have sufficient survey data to include all 33 service areas. Third, even if data were available on all 33 service areas, these areas could still prove to be too large to identify between-area differences in mistargeting. Large areas of geography tend to be heterogeneous with low levels of between area differences whereas small areas of geography tend to be homogeneous with higher levels of between-area differences (Duncan \& Jones, 2000). Indeed, a UK multilevel analysis of mental disorders only determined variability at the individual and household level and not at the electoral ward level and concluded that these wards were likely too large (Weich et al., 2003). It is likely that our estimate of between-area variation in targeting is a minimum estimate as the administrative areas used may be poorly aligned with the actual geography of targeting. While using a lower level of geography might prove more fruitful, it would result in an inability to tie inferences to an administrative level of geography at which policy is made. The challenge is to delineate geographical boundaries that map into differences in the variables of interest. This is a challenge for anyone trying to do 'actionable' research constrained by administrative geographical boundaries that might be the level at which policy operates, but that might not make sense in relation to the object of study, in our case targeting.

Fourth, a challenge to geographic epidemiology in mental health observed by Holley (1998) also applies here. Namely, there is a limited choice of indicators at the area-level. Indicators likely relevant to our research questions were either unavailable (e.g. average distance travelled to services could be assessed if specific postal code or geographic coordinates of households and services were available), or available but not appropriate to be used at the arealevel (e.g. the OCHS study asked questions about perceived barriers to service use but they were only asked of a small subset of individuals who felt they needed help in the past but had not sought services leading to a very small sample to base aggregations on). 
Finally, the relationship between mental health need and service contact is complicated when they are assessed concurrently and with the same reference period as they are in the current study. There may be cases where need is absent and the service contact is present (i.e. occurred within the 6 months prior to the study interview) because the need was already addressed. Similarly, we cannot assume that concurrent need and service contact need means that the need is being effectively addressed. The need could continue to be unmet, even with treatment, if that treatment is not appropriate or effective. These are not issues that we can address due to the cross-sectional nature of the data. But, we can assume that even if service targeting is not perfect for the reasons outlined above, these reasons should at least be consistent across service areas.

There are many opportunities for novel and innovative research in this largely neglected area. This type of work holds promise for generating new policy-relevant knowledge that can inform mental health service provision. The increasing availability of administrative data and individual-level location tracked information could address some of the limitations identified.

\section{Conclusion}

In addressing existing knowledge gaps, this study uncovered geographic inequities in children's mental health service targeting (the extent to which children with a mental health need are not in contact with mental health services and children without a mental health need are in contact with services), and identified areas of policy focus that could improve service targeting. These include providing additional support to service areas outside of Toronto and in rural areas to increase the ability of agencies in those areas to target their services more effectively children with a mental health need. Targeting also seems to be less effective for non-intensive services suggesting that these services might benefit from a review of service definition or eligibility criteria. Area-level antisocial behaviour and satisfaction with area services and resources were 


\section{GEOGRAPHIC VARIATION IN SERVICE TARGETING}

identified as external, environmental correlates of targeting that could be indicative of other organizational or social instability worthy of policy intervention.

Ethical approval: All procedures performed in studies involving human participants were in accordance with the ethical standards of the institutional research committee (Hamilton Integrated Research Ethics Board 13-140), Statistics Canada's Statistics Act and with the 1964 Helsinki declaration and its later amendments or comparable ethical standards.

Informed Consent: Informed consent was obtained from all individual participants included in the study. 
GEOGRAPHIC VARIATION IN SERVICE TARGETING

\section{References}

Achenbach, T. M. (1991). Manual for the Child Behavior Checklist/4-18 and 1991 profile. Burlington, VT: Department of Psychiatry, University of Vermont.

Andersen, R. M. (1995). Revisiting the behavioral model and access to medical care: does it matter? Journal of Health and Social Behavior, 36, 1-10. https://doi.org/10.2307/2137284

Andersen, R. M. (2008). National health surveys and the behavioral model of health services use. Medical Care, 46(7), 647-653. https://doi.org/10.1097/mlr.0b013e31817a835d

Andersen, R., \& Newman, J. F. (1973). Societal and individual determinants of medical care utilization in the United States. The Milbank Memorial Fund Quarterly. Health and Society, 51(1), 95-124. https://doi.org/10.2307/3349613

Babitsch, B., Gohl, D., \& von Lengerke, T. (2012). Re-revisiting Andersen's Behavioral Model of Health Services Use: a systematic review of studies from 1998-2011. GMS PsychoSocial-Medicine, 9(11). https://doi.org/10.3205/psm000089

Benjamini, Y., \& Hochberg, Y. (1995). Controlling the false discovery rate: a practical and powerful approach to multiple testing. Journal of the Royal Statistical Society: series B (Methodological), 57(1), 289-300. https://doi.org/10.1111/j.2517-6161.1995.tb02031.x

Bhattacharya, D., \& Bhatt, J. (2017). Seven foundational principles of population health policy. Population Health Management, 20(5), 383-388. https://doi.org/10.1089/pop.2016.0148

Boydell, K. M., Pong, R., Volpe, T., Tilleczek, K., Wilson, E., \& Lemieux, S. (2006). Family perspectives on pathways to mental health care for children and youth in rural communities. The Journal of Rural Health, 22(2), 182-188. https://doi.org/10.1111/j.1748-0361.2006.00029.x 
Boyle, M. H., Duncan, L., Georgiades, K., Wang, L., Comeau, J., Ferro, M. A., ... \& Janus, M. (2018). The 2014 Ontario Child Health Study Emotional Behavioural Scales (OCHSEBS) part II: psychometric adequacy for categorical measurement of selected DSM-5 disorders. The Canadian Journal of Psychiatry, https://doi.org/10.1177/0706743718808251

Boyle, M. H., Georgiades, K., Duncan, L., Comeau, J., Wang, L., \& 2014 Ontario Child Health Study Team. (2019a). The 2014 Ontario Child Health Study—methodology. The Canadian Journal of Psychiatry, 64(4), 237-245. https://doi.org/10.1177/0706743719833675

Boyle, M. H., Georgiades, K., Duncan, L., Wang, L., Comeau, J., \& 2014 Ontario Child Health Study Team. (2019b). Poverty, neighbourhood antisocial behaviour, and children's mental health problems: findings from the 2014 Ontario Child Health Study. The Canadian Journal of Psychiatry, 64(4), 285-293. https://doi.org/10.1177/0706743719830027

Bradshaw, J. (1972). Taxonomy of social need. In G. McLachlan (Ed.), Problems and progress in medical care: essays on current research, 7th Series. (pp. 71-82) London, UK: Oxford University Press.

Bradshaw, J. (2005). The conceptualization and measurement of need: a social policy perspective. In J. Popay \& G. Williams (Eds.) Researching the people's health. (pp. 5770) London, UK: Routledge

Canadian Mental Health Association. (2009). Rural and northern community issues in mental health. CMHA Public Policy: Backgrounders, ed. Rural and Northern Advisory Committee. Toronto: Canadian Mental Health Association, 1-11. Retrieved from 

How healthy are rural Canadians? An assessment of their health status and health determinants. Ottawa, ON: Canadian Institute for Health Information.

Duncan, C., \& Jones, K. (2000). Using multilevel models to model heterogeneity: potential and pitfalls. Geographical Analysis, 32(4), 279-305. https://doi.org/10.1111/j.15384632.2000.tb00429.x

Duncan, L., Georgiades, K., Wang, L., Van Lieshout, R. J., MacMillan, H. L., Ferro, M. A., ... \& Janus, M. (2018). Psychometric evaluation of the Mini International Neuropsychiatric Interview for Children and Adolescents (MINI-KID). Psychological Assessment, 30(7), 916-928 https://doi.org/10.1037/pas0000541

Duncan, L., Georgiades, K., Wang, L., Comeau, J., Ferro, M. A., Van Lieshout, R. J., ... \& Janus, M. (2018). The 2014 Ontario Child Health Study Emotional Behavioural Scales (OCHSEBS) Part I: A Checklist for Dimensional Measurement of Selected DSM-5 Disorders. The Canadian Journal of Psychiatry, https://doi.org/10.1177/0706743718808250

Fleury, M. J., Grenier, G., Bamvita, J. M., Perreault, M., Kestens, Y., \& Caron, J. (2012). Comprehensive determinants of health service utilisation for mental health reasons in a Canadian catchment area. International Journal for Equity in Health, 11(1), 20. https://doi.org/10.1186/1475-9276-11-20

Flisher, A. J., Kramer, R. A., Grosser, R. C., Alegria, M., Bird, H. R., Bourdon, K. H., ... \& Narrow, W. E. (1997). Correlates of unmet need for mental health services by children 
GEOGRAPHIC VARIATION IN SERVICE TARGETING

and adolescents. Psychological Medicine, 27(5), 1145-1154.

https://doi.org/10.1017/s0033291797005412

Georgiades, K., Duncan, L., Wang, L., Comeau, J., Boyle, M. H., \& 2014 Ontario Child Health

Study Team. (2019). Six-month prevalence of mental disorders and service contacts

among children and youth in Ontario: evidence from the 2014 Ontario Child Health

Study. The Canadian Journal of Psychiatry, 64(4), 246-255.

https://doi.org/10.1177/0706743719830024

Government of Ontario. (2015). Community-based child and youth mental health - Program

guidelines and requirements \#01: Core services and key processes. Retrieved from

http://www.children.gov.on.ca/htdocs/English/documents/specialneeds/mentalhealth/pgr1

.pdf.

Holley, H. L. (1998). Geography and mental health: a review. Social Psychiatry and Psychiatric Epidemiology, 33(11), 535-542.

Howell, E., \& McFeeters, J. (2008). Children's mental health care: Differences by race/ethnicity in urban/rural areas. Journal of Health Care for the Poor and Underserved, 19(1), 237247. https://doi.org/10.1353/hpu.2008.0008

Kataoka, S. H., Zhang, L., \& Wells, K. B. (2002). Unmet need for mental health care among US children: Variation by ethnicity and insurance status. American Journal of Psychiatry, 159(9), 1548-1555. https://doi.org/10.1176/appi.ajp.159.9.1548

Kreft, I. G. G. (1996). Are multilevel techniques necessary? An overview, including simulation studies. Unpublished manuscript, California State University, Los Angeles.

Law, J., \& Perlman, C. (2018). Exploring geographic variation of mental health risk and service utilization of doctors and hospitals in Toronto: a shared component spatial modeling 


\section{GEOGRAPHIC VARIATION IN SERVICE TARGETING}

approach. International Journal of Environmental Research and Public Health, 15(4), 593. https://doi.org/10.3390/ijerph15040593

Maas, C. J., \& Hox, J. J. (2005). Sufficient sample sizes for multilevel modeling. Methodology, 1(3), 86-92. https://doi.org/10.1027/1614-2241.1.3.85

McNeish, D. M., \& Stapleton, L. M. (2016). The effect of small sample size on two-level model estimates: A review and illustration. Educational Psychology Review, 28(2), 295-314. https://doi.org/10.1007/s10648-014-9287-x

Mitura, V., \& Bollman, R. (2004). Health status and behaviours of Canada's youth: a ruralurban comparison. Statistics Canada, Agriculture Division. Retrieved from http://publications.gc.ca/site/eng/257736/publication.html

Nagarajan, K. V. (2004). Rural and remote community health care in Canada: beyond the Kirby Panel Report, the Romanow Report and the federal budget of 2003. Canadian Journal of Rural Medicine, 9(4), 245-251.

Newacheck, P. W., Hughes, D. C., Hung, Y. Y., Wong, S., \& Stoddard, J. J. (2000). The unmet health needs of America's children. Pediatrics, 105(Supplement 3), 989-997.

Phillips, K. A., Morrison, K. R., Andersen, R., \& Aday, L. A. (1998). Understanding the context of healthcare utilization: assessing environmental and provider-related variables in the behavioral model of utilization. Health Services Research, 33(3 Pt 1), 571-596.

Pong, R. W., DesMeules, M., \& Lagacé, C. (2009). Rural-urban disparities in health: How does Canada fare and how does Canada compare with Australia? Australian Journal of Rural Health, 17(1), 58-64. https://doi.org/10.1111/j.1440-1584.2008.01039.x

Rasbash, J., Steele, F., Browne, W., \& Prosser, B. (2004). A user's guide to MLwiN Version 2. London, UK: Institute of Education 
Reid, G. J., Tobon, J. I., \& Shanley, D. C. (2008). What is a mental health clinic? How to ask parents about help-seeking contacts within the mental health system. Administration and Policy in Mental Health and Mental Health Services Research, 35(4), 241-249. https://doi.org/10.1007/s10488-008-0165-Z

Sheehan, D. V., Sheehan, K. H., Shytle, R. D., Janavs, J., Bannon, Y., Rogers, J. E., ... \& Wilkinson, B. (2010). Reliability and validity of the mini international neuropsychiatric interview for children and adolescents (MINI-KID). The Journal of Clinical Psychiatry, 71(3) 313-326. https://doi.org/10.4088/jcp.09m05305whi

Statistics Canada. (2017a). 2014 Ontario Child Health Study (Master File). Statistics Canada. Survey No. 3824.

Statistics Canada. (2017b).Microdata User Guide 2014 Ontario Child Health Study. Ottawa $(\mathrm{ON})$ : Special Surveys Division.

Statistics Canada. (2018). Census Profile, 2016 Census. Statistics Canada. Catalogue no. 98-316X2016001

Sterne, J. A., White, I. R., Carlin, J. B., Spratt, M., Royston, P., Kenward, M. G., ... \& Carpenter, J. R. (2009). Multiple imputation for missing data in epidemiological and clinical research: potential and pitfalls. BMJ, 338, b2393-b2393. https://doi.org/10.1136/bmj.b2393

Sturm, R., Ringel, J. S., \& Andreyeva, T. (2003). Geographic disparities in children's mental health care. Pediatrics, 112(4), e308-e308. https://doi.org/10.1542/peds.112.4.e308

Waddell, C., Shepherd, C., Schwartz, C., \& Barican, J. (2014). Child and youth mental disorders: Prevalence and evidence-based interventions. Vancouver, BC: Children's Health Policy Centre, Simon Fraser University. 
Weich, S., Holt, G., Twigg, L., Jones, K., \& Lewis, G. (2003). Geographic variation in the prevalence of common mental disorders in Britain: a multilevel investigation. American Journal of Epidemiology, 157(8), 730-737. https://doi.org/10.1093/aje/kwg035

Wichstrøm, L., Belsky, J., \& Jozefiak, T. (2014) Predicting service use for mental health problems among young children. Pediatrics, 133(6), 2013-3184.

https://doi.org/10.1542/peds.2013-3184d

World Health Organization. (2000). The world health report 2000: health systems: improving performance. Public Health Reports 116(3) 268-269. https://doi.org/10.1016/s00333549(04)50043-2 
Table 1. Sociodemographic \& Service Area Characteristics of Study Sample

\begin{tabular}{lc}
\hline Characteristics & Mean/\% (SE) \\
\hline Children $(\mathrm{n}=10,765)^{1}$ & $51.0(0.87)$ \\
Male, \% & $10.4(0.07)$ \\
Age in years, mean & $19.3(0.69)$ \\
With mental health need, \% & $3.5(0.34)$ \\
With mental health service contact, \% & $82.7(0.65)$ \\
Service targeting, \% & $80.0(0.69)$ \\
$\quad$ No need \& no service contact, \% & $2.7(0.31)$ \\
$\quad$ Need \& service contact, \% & $17.3(0.65)$ \\
Service mistargeting, \% & $0.8(0.15)$ \\
$\quad$ No need \& service contact, \% & $16.5(0.64)$ \\
$\quad$ Need \& no service contact, \% & Mean (SD) \\
\hline Service Areas (n=28) &
\end{tabular}

System characteristics

Mental health service expenditures

$\$ 11,395,785(14,074,562)$

[\$1M-\$76M]

Number of children's mental health agencies

$8.96(15.44)$

Types of services received

$\%$ Clients receiving brief services

$33.3(16.2)$

$[0.5-61.6]$

\% Clients receiving counselling/therapy services $46.0(16.7)$

$[9.1-97.1]$

\% Clients receiving crisis services

$22.9(21.2)$

[0-75.4]

$\%$ Clients receiving intensive treatment services

$15.7(17.7)$

$[1.8-100]$ 


\section{GEOGRAPHIC VARIATION IN SERVICE TARGETING}

Levels of antisocial behaviour $\quad 0.6(0.3)$

[0.13-1.12]

Levels of satisfaction with services \& resources $\quad 8.8(1.0)$

$[6.63-10.72]$

Socio-demographic characteristics

Number of children $0-18$

$97,529(113,749)$

$[19,116-524,876]$

$\%$ Immigrants

$17.0(13.2)$

$\%$ Rural population

$27.3(20.1)$

[0-62.2]

$\%$ Single parent families

$16.3(2.3)$

[13.3-21.2]

$\%$ Rental dwellings

$26.1(6.6)$

[14.2-47.2]

Mean household income

$\$ 90,803(14,797)$

$[\$ 72,831-\$ 139,315]$

$\mathrm{SE}=$ Standard Error, $\mathrm{SD}=$ Standard Deviation

${ }^{1}$ For individual child variables, descriptives reported are means/percentages of all individuals

${ }^{2}$ For service area variables, descriptives reported are means across 28 service areas 
Table 2. Weighted Fixed Effect Estimates and 95\% Confidence Intervals for Binary Logistic

Multilevel Models of Service Mistargeting for all Individuals $(n=10,765)^{\text {a }}$

\begin{tabular}{ll}
\hline Service Area Characteristics & Unadjusted OR $(95 \% \mathrm{CI})^{\mathrm{b}}$ \\
\hline System characteristics & $1.01(1.01-1.01)^{* * *}$ \\
Mental health services expenditures $(\$ \mathrm{Ms})$ & $1.01(1.01-1.01)^{* * *}$ \\
Number of children's mental health agencies & \\
Types of services received (10\% increments) & \\
$\%$ Receiving brief services & $0.98(0.91-1.05)$ \\
$\%$ Receiving counselling/therapy services & $0.94(0.87-1.02)$ \\
$\%$ Receiving crisis services & $1.06(0.98-1.16)$ \\
$\%$ Receiving intensive treatment services & $1.07(1.02-1.13)^{* *}$ \\
Toronto & $1.75(1.53-1.99)^{* * *}$
\end{tabular}

\section{Environmental characteristics}

Antisocial behaviour $\quad 0.45(0.27-0.75)^{* *}$

Satisfaction with services \& resources $\quad 1.28(1.14-1.43) * * *$

Socio-demographic characteristics
Number of children 0-18 (10,000s)
$1.01(1.01-1.02) * * *$
$\%$ immigrants $(10 \%$ increments $)$
$1.01(1.01-1.02)^{* *}$
$\%$ rural population $(10 \%$ increments)
$0.91(0.86-0.96)^{* *}$
$\%$ single parent families (10\% increments)
$1.00(0.92-1.09)$
$\%$ rental dwellings (10\% increments)
$1.00(0.97-1.03)$
Mean household income $(\$ 10,000$ s)
$1.14(1.05-1.23)^{* *}$

Note. ${ }^{*} p<0.05, * * p<0.01, * * * p<0.001, \mathrm{OR}=$ Odds ratio, $\mathrm{CI}=$ confidence interval 


\section{GEOGRAPHIC VARIATION IN SERVICE TARGETING}

${ }^{\text {a }}$ Level 1 and Level 2 intercepts are not shown as each variable was added to the model one at a time.

${ }^{\mathrm{b}}$ All effects are robust to $p$ value adjustment for multiple testing 

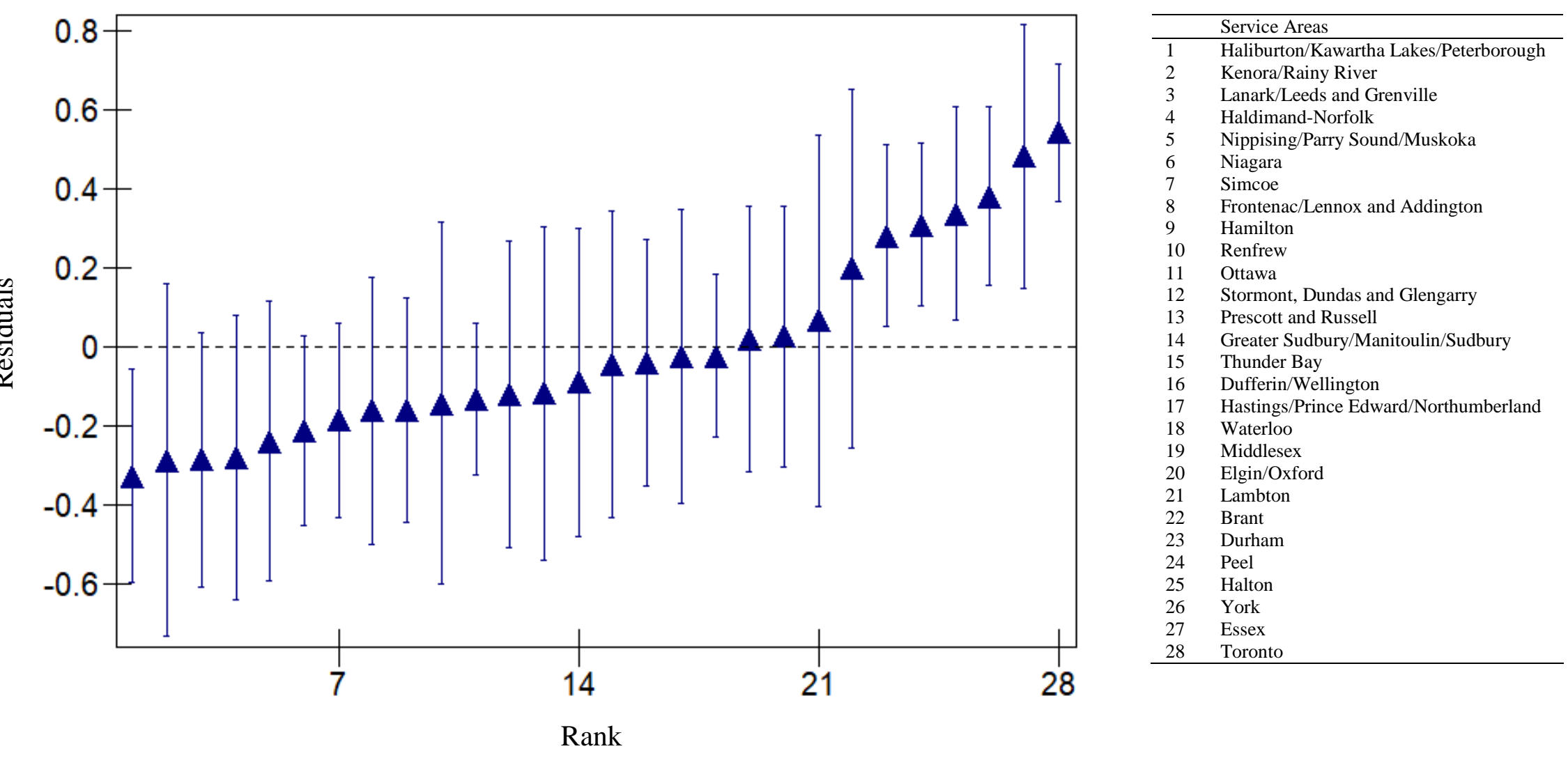

Figure 1. Residual plot of random effects and service area ranking

The plot shows the residuals in ascending order, from the lowest levels of targeting to the highest, along with their $95 \%$ confidence limits. The residuals indicate how far service area levels of targeting depart from the overall mean (the dotted line in the middle of the graph reflects mean service targeting in Ontario). 
Brant

Dufferin/Wellington

Durham

Elgin/Oxford

Essex

Frontenac/Lennox and Addington

Haldimand-Norfolk

Haliburton/Kawartha Lakes/Peterborough

Halton

Hamilton

Hastings/Prince Edward/Northumberland

Kenora/Rainy River
Environmental

Types of services received characteristics
nate

Socio-demographic characteristics

\begin{tabular}{|c|c|c|c|c|c|c|c|c|c|c|c|c|c|}
\hline 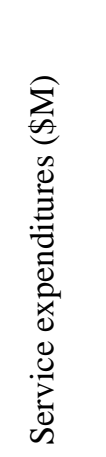 & 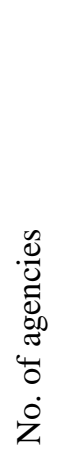 & 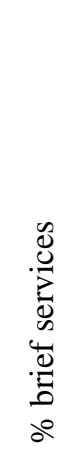 & 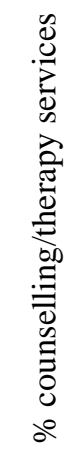 & 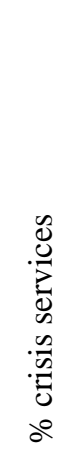 & 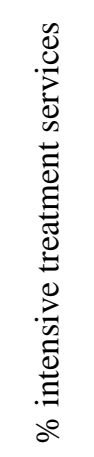 & 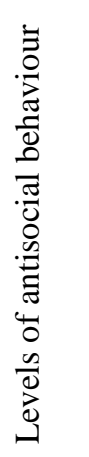 & 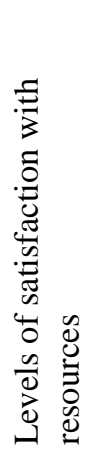 & 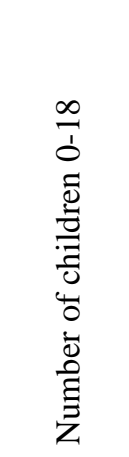 & 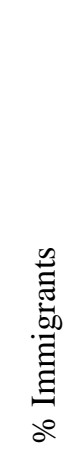 & 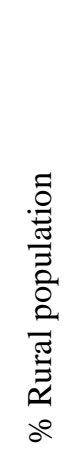 & 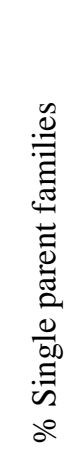 & 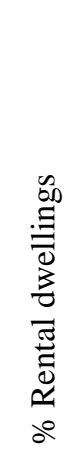 & 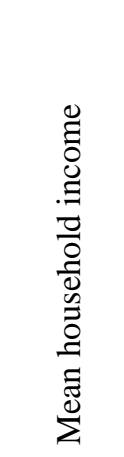 \\
\hline $1.1 \mathrm{M}$ & 4 & 49.1 & 9.1 & 39.2 & 100.0 & 0.43 & 8.82 & 31,655 & 12.5 & 15.6 & 18.5 & 27.6 & 83,028 \\
\hline $4.7 \mathrm{M}$ & 2 & 26.7 & 43.4 & 21.6 & 8.6 & 0.31 & 9.25 & 63,253 & 16.4 & 24.6 & 14.1 & 24.3 & 101,786 \\
\hline $9.5 \mathrm{M}$ & 7 & 15.5 & 37.5 & 12.1 & 27.3 & 0.58 & 9.10 & 149,454 & 23.6 & 8.4 & 18.2 & 18.8 & 106,886 \\
\hline $3.1 \mathrm{M}$ & 3 & 53.5 & 40.5 & 18.6 & 11.9 & 0.42 & 9.22 & 46,809 & 10.8 & 33.3 & 14.3 & 25.5 & 81,748 \\
\hline $6.4 \mathrm{M}$ & 5 & 30.1 & 56.8 & 37.2 & 12.3 & 0.13 & 10.39 & 85,815 & 21.9 & 12.4 & 18.4 & 27.2 & 85,824 \\
\hline $6.0 \mathrm{M}$ & 2 & 49.6 & 55.5 & 3.7 & 8.1 & 0.81 & 8.20 & 37,150 & 10.8 & 34.7 & 15.7 & 31.7 & 85,246 \\
\hline $7.2 \mathrm{M}$ & 6 & 5.4 & 58.1 & 38.4 & 17.9 & 1.07 & 8.68 & 38,069 & 9.8 & 30.8 & 13.4 & 18.7 & 83,669 \\
\hline $2.2 \mathrm{M}$ & 2 & 61.6 & 34.1 & 55.4 & 9.5 & 0.98 & 8.11 & 22,265 & 8.3 & 54.7 & 14.7 & 22.5 & 78,563 \\
\hline $9.9 \mathrm{M}$ & 10 & 20.6 & 45.5 & 18.9 & 17.8 & 0.44 & 9.31 & 40,420 & 29.6 & 47.7 & 13.4 & 19.1 & 139,315 \\
\hline $14.2 \mathrm{M}$ & 12 & 45.6 & 27.9 & 11.3 & 9.7 & 0.20 & 10.72 & 133,918 & 24.7 & 4.4 & 19.2 & 32.4 & 87,775 \\
\hline $13.9 \mathrm{M}$ & 16 & 32.2 & 66.6 & 75.4 & 29.2 & 0.85 & 8.19 & 112,858 & 8.6 & 6.5 & 14.6 & 23.8 & 82,073 \\
\hline $7.4 \mathrm{M}$ & 7 & 15.0 & 59.6 & 2.9 & 8.2 & 0.35 & 6.78 & 45,045 & 4.2 & 48.4 & 21.2 & 20.6 & 79,823 \\
\hline
\end{tabular}




\section{Click here to access/download \\ Supplementary material CoverLetter_190606.doc}

